\title{
Antibacterial Property of Hot and Cold Extracted Turmeric Extract: An In-Vitro Study
}

\author{
S.S. Mahour*, S.P. Nema, Daljeet Chhabra, Anavil Bhardwaz and S.K. Karmore
}

Department of Veterinary Gynaecology and Obstetrics, College of Veterinary Science and Animal Husbandry, Mhow (M.P.), India

*Corresponding author

\begin{tabular}{|l|}
\hline K e y w o r d s \\
Turmeric, Curcumin, \\
$\begin{array}{l}\text { MIC, Ethanol extract, } \\
\text { Staphylococcus aureous, } \\
\text { Double dilution }\end{array}$ \\
\hline Article Info \\
\hline $\begin{array}{l}\text { Accepted: } \\
\text { 24 September } 2018 \\
\text { Available Online: } \\
\text { 10 October } 2018\end{array}$ \\
\hline
\end{tabular}

\section{A B S T R A C T}

The present study was conducted to assess the minimum inhibitory concentration of ethanolic extract of turmeric obtained from hot and cold extraction method on staphylococcus aureus pure culture. Ethanolic extract of turmeric was prepared and stock solution was made in the distilled water containing $100 \mathrm{mg} / \mathrm{ml}$ of turmeric extract. Stock solution was further subjected to double dilution method up to10 times. Sterile antibiotic sensitivity disc containing different concentration of turmeric extract were subjected to antibiotic sensitivity test on pure culture of staphylococcus aureus bacteria. After overnight incubation of culture plates an inhibitory zone were appeared around the disc no. $1,2,3$ and 4 (concentration 100, 50, 25 and $12.5 \mathrm{mg} / \mathrm{ml}$ ) with hot extracted turmeric extract and disc no. 1, 2 and 3 (concentration $100 \mathrm{mg}, 50 \mathrm{mg}$ and $25 \mathrm{mg} / \mathrm{ml}$ with cold extracted turmeric extract. With this in-vitro study, we concluded that ethanolic extract, extracted with hot and cold extraction method have antibacterial property against staphylococcus aureus bacteria. The MIC (minimum inhibitory concentration) value was at $12.5 \mathrm{mg} / \mathrm{ml}$ with hot extracted turmeric extract while MIC value with cold extracted extract was found $25 \mathrm{mg} / \mathrm{ml}$. Thus study revealed that turmeric extract with hot extraction gives MIC at lower concentration than cold extracted turmeric extract on pure culture of staphylococcus aureus bacteria.

\section{Introduction}

The turmeric (Curcuma longa) is a native plant of southern Asia and is cultivated extensively throughout the warmer parts of the world. It belongs to family Zingiberaceae.

Rhizomes of turmeric plant contain 3-4\% volatile oil with unique aromatic characteristics. Curcumin is the main biologically active curcuminoid phytochemical compound of turmeric which is responsible for yellow color of the root. In fact, it is the curcuminoids that possess all the bio-protective properties in turmeric (Badmaev et al., 2004). Turmeric has long been used as a powerful anti-inflammatory in both the Chinese and Indian systems of medicine (Gescher et al., 2005). Turmeric is also documented to have wound healing capacity (Biswas and Mukherjee, 2003).

Turmeric, have been examined for their inhibitory action against the microorganisms 
(antimicrobial activity) responsible for food spoilage and food borne illnesses (Grag and Menon, 2003). In this study, alcoholic extract of turmeric extracted with hot and cold extraction method were evaluated for its invitro antibacterial property on Staphylococcus aureous bacteria and the quality of hot and cold extracted extract were also evaluated by using MIC (minimum inhibitory concentration) value.

\section{Materials and Methods}

\section{Plant material}

The whole dried rhizome of turmeric was purchased from the local market. Rhizome was grinded and fine powder was made in the mixer grinder. Then powder was strained in the sieve to separate coarse particle.

\section{Preparation of extract}

\section{Hot extraction}

$10 \mathrm{gm}$ of prepared turmeric powder was taken in a thimble made from a filter paper. Thimble is fitted in soxhlet assembly for extraction. After $8 \mathrm{hrs}$ extraction procedure at $70^{\circ} \mathrm{C}$ with ethanol, a semisolid sticky, dark brown color turmeric extract was obtained in an oil flask. Obtained extract in oil flask was transferred in a tube with the help of adding some ethanol which was further allowed to evaporate at room temperature. Resulted extract were used to prepare stock solution in distilled water containing $100 \mathrm{mg}$ of turmeric extract per ml of distilled water, which were further used for the double dilution procedure.

\section{Cold extraction}

Prepared turmeric powder was taken in a conical flask and $100 \mathrm{ml}$ ethanol was added and kept at room temperature for one week, occasional shaking was done. Such prepared solution was filtered with muslin cloth and then with filter paper. Ethanol was allowed to evaporate till we obtained semisolid extract.

Because of hydrophobic nature of turmeric extract few $\mathrm{ml}$ of tween-80 and few $\mathrm{mg}$ of carboxy methyl cellulose were added to make the even suspension of turmeric extract.

\section{Preparation of dilutions}

The stock solution of turmeric extract obtained from hot and cold extraction procedure were subjected to prepare various dilutions with distilled water following double dilution method, containing turmeric extracts as 100, $50,25,12.5,6.25,3.125,1.56,0.781,0.390$ and $0.195 \mathrm{mg} / \mathrm{ml}$.

\section{Preparation of antibiotic sensitivity disc}

Sterile antibiotic sensitivity discs (Himedia) were soaked in different dilutions of extract for $24 \mathrm{hrs}$ at room temperature. Discs were removed, dried completely and given a number to each disc.

Evaluation of antimicrobial activity (MIC: minimum inhibitory concentration)

Prepared discs were used for antibacterial activity test. The antibiotic sensitivity discs prepared from different dilution of turmeric extract were placed over Mueller Hinton agar media, inoculated with pure culture of staphylococcus aureus bacteria. After overnight incubation zone of inhibition of each disc was noted.

\section{Results and Discussion}

Staphylococcus aureus is a Gram-positive, round-shaped bacterium. It is a member of the normal flora of the body, frequently found in the nose, respiratory tract and on the skin. It may cause various diseases of human and 
animals, commonly skin infections, respiratory and lower genital infections. The emergence of antibiotic resistant strains of $S$. aureus is a worldwide problem in clinical medicine (https://en.wikipedia.org/wiki/ Staphylococcus_aureus). Due to the drug resistance of several antimicrobials and possibility of side effects are the facts that turned the attention of scientists to use the herbal medicine for treatment of diseases. Turmeric is used as traditional medicine for the treatment of inflammatory conditions. In the present study antibiotic sensitivity disc 1 , 2, 3 and 4 (concentration 100, 50, 12.5 and $6.25 \mathrm{mg}$ ) had shown zone of inhibition on staphylococcus pure culture with turmeric extract obtained from hot extraction. Antibiotic sensitivity disc1, 2 and 3 (con. 100, 50 and $25 \mathrm{mg}$ ) had also shown zone of inhibition with turmeric extract obtained from cold extraction. Present study revealed that turmeric extract obtained from hot and cold extraction has antibacterial property, against staphylococcus bacteria. Similar finding was also reported by Hegde et al., (2012) who reported that hydro-alcoholic and aqueous

Plate.1 Inhibitory zone around disc no. 1, 2, and 3 (Hot extraction)

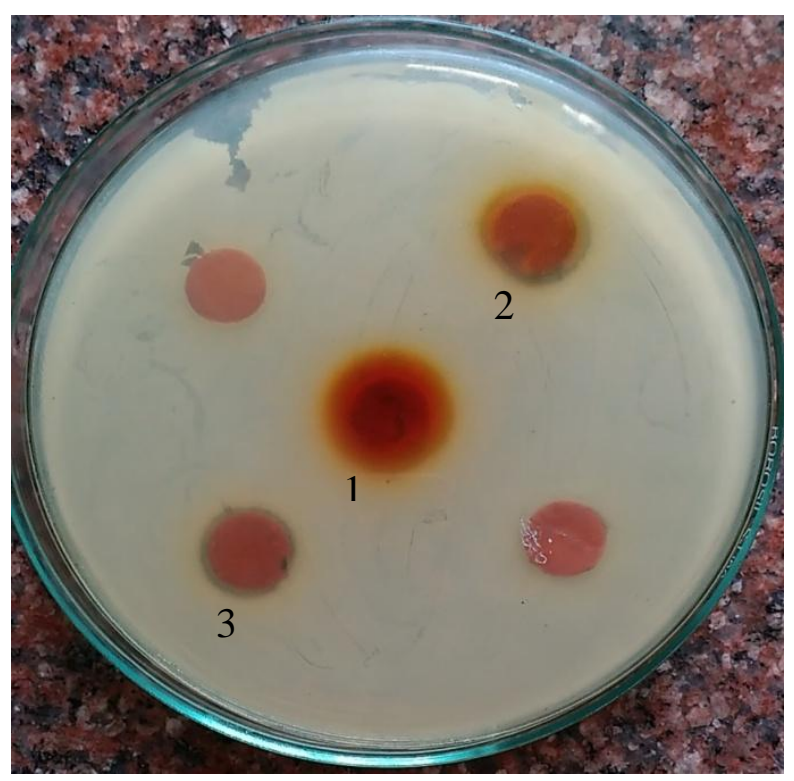

extract of turmeric showed inhibitory activity against Staphylococcus aureus. Present findings also revealed that turmeric extract, extracted from hot extraction with ethanol exhibited antibacterial activity at lower concentration as compared to the cold extracted turmeric extract. Singh et al., (2002) also reported the antimicrobial activity of curcuma longa rhizome extract against Staphylococcus aureus, Staphylococcus epidermis, Escherichia coli, Pseudomonas aeruginosa and Salmonella typhimurium.

Kumar (2016) reported the minimum inhibitory concentration (MIC) values of hydro alcoholic extract of turmeric against bacterial population in cervical mucus of repeat breeding cows suffering from subclinical endometritis were 12.50.-25.0 $\mathrm{mg} / \mathrm{ml}$

The results obtained with turmeric extract obtained from cold extraction are in close accordance with the findings of Nkambule (2008) who found MIC of turmeric extract at $20 \mathrm{mg}$ concentration.

Plate.2 Inhibitory zone around disc no. 4 (Hot extraction)




Plate.3 Inhibitory zone around disc no. 1, 2 and 3 (cold extraction)

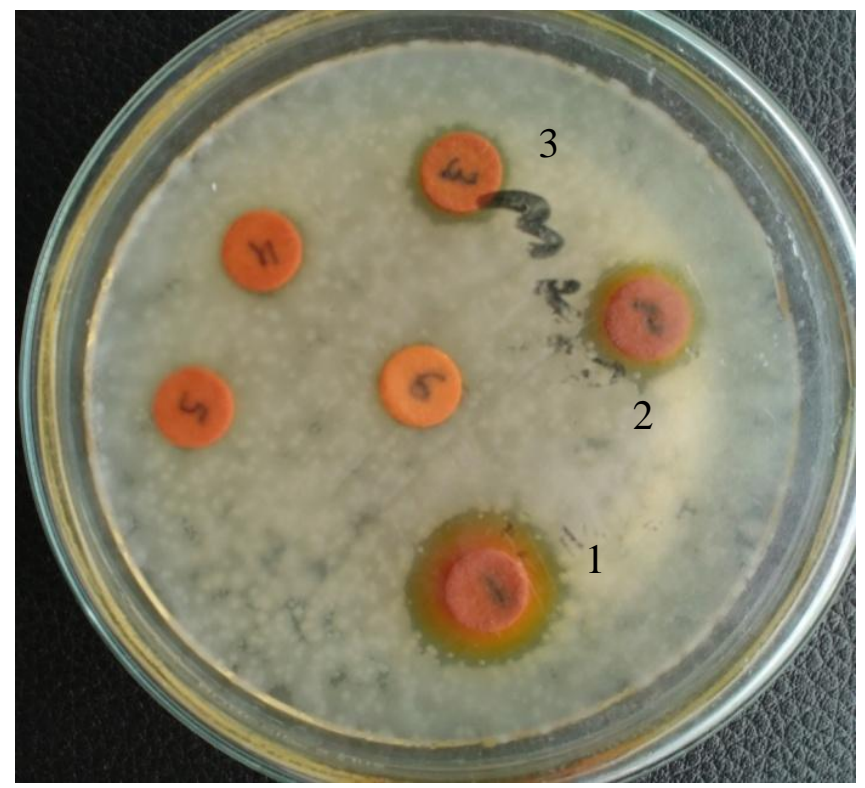

The present in-vitro study were conducted with the objectives to know the difference between the anti-microbial activity of turmeric extract obtained from the hot and cold extraction method with minimum inhibitory concentration of turmeric extract followed by double dilution method.

The results showed that turmeric extract, extracted from hot extraction method (soxhelet extraction) gives MIC at lower concentration $(12.5 \mathrm{mg} / \mathrm{ml})$ than extract obtained from cold extraction $(25 \mathrm{mg} / \mathrm{ml})$ on staphylococcus aureus bacteria.

With this study we also concluded that turmeric extract have antibacterial property against staphylococcus bacteria.

\section{Acknowledgement}

We convey our thanks to the head and whole faculty of Department of Veterinary Gynaecology and Obstetrics, Department of Veterinary Microbiology of College of Veterinary Science \& A.H., Mhow, for providing necessary facilities for the study.

\section{References}

Badmaev, V., Majeed, M., Prakash, L. (2004) Curcuminoids: bioactive compounds from turmeric. Sabinsa Corporation, 2.

Biswas, T.K., Mukherjee, B. (2003) Plant medicines of Indian origin for wound healing activity: A healing review. International Journal of Lower Extremity Wounds 2(1): 25-39.

Gescher, A., Sharma, R. and Steward, W. (2005) Curcumin: the story so far. European Journal of Cancer 41(13): 1955-1968.

Grag, S.R. and Menon, K.V. (2003). Spices and herbs- promising antimicrobial agents and natural food preservatives. Haryana Agricultural University Journal of Research 3 (1): 1-6.

Hedge, M.N., Shetty, S., Yelapure, M. and Patil, A. (2012). Evaluation of antimicrobial activity of aqueous and hydro-alcoholic Curcuma longa extracts against endodontic pathogens. IOSR Journal of Pharmacy 2 (2): 192-198.

Kumar, R. (2016). Studies on the immunomodulatory \& therapeutic 
efficacy of ashwagandha (Withania somnifera), garlic (Allium sativum) \& turmeric (curcuma longa) on endometritic repeat breeding crossbred cows. A Ph.D. thesis submitted to the Birsa Agricultural University, Kanke, Ranchi, Jharkhand
Nkambule, T.P. (2008). Antimicrobial properties of selected Asian herbs. M. Sc. Thesis. University of Florida.

Singh, R., Chandra, R., Bose, M., and Luthra, P.M. (2002). Antibacterial activity of curcuma longa rhizome extract on pathogenic bacteria. Current Sciences 83 (6): 25.

\section{How to cite this article:}

Mahour, S.S., S.P. Nema, Daljeet Chhabra, Anavil Bhardwaz and Karmore, S.K. 2018. Antibacterial Property of Hot and Cold Extracted Turmeric Extract: An In-Vitro Study. Int.J.Curr.Microbiol.App.Sci. 7(10): 3147-3151. doi: https://doi.org/10.20546/ijcmas.2018.710.364 